\title{
IMMERSIVE LEARNING FOR TEACHER EDUCATION
}

\author{
Eric Tarantini \\ University of St.Gallen, St. Jakobstrasse 21, 9000 St.Gallen, Switzerland
}

\begin{abstract}
Virtual Reality technology (VR) offers new potentials for immersive learning and teaching. Nevertheless, its concrete use in education still lacks of a theoretical foundation and use cases. The present contribution describes the creation of a framework based on the concepts of Storytelling and immersive Learning to set a base for the beneficial use of VR in education. Furthermore, those results are transferred to the field of teacher education. Key findings are that (I): Educational Storyliving represents a promising method to be used for a didactically beneficial use of VR in education, (II): VR inherits the characteristic to foster the teaching of emotional and classroom management skills for novice teachers.
\end{abstract}

\section{KEYWORDS}

Immersive Learning, Digital Storytelling, Storyliving, Virtual Reality, Teacher Education

\section{INTRODUCTION}

Virtual Reality (VR) provides new perspectives in teaching and learning. It offers the opportunity to depict immersive worlds of experience and to immerse oneself in them (Hodgson et al., 2019; Parker et al., 2016; Google News Lab, 2017). Recent research efforts show, that immersive technologies are likely to produce positive emotions when used properly, which potentially lead to a relatively higher user performance (Hwang et al., 2016; Nissim \& Weissblueth, 2017; Suh \& Prophet, 2018). Moreover, it indicates that immersive pedagogy can be effectively strengthened and enabled by using VR (Schmoelz, 2018; Parker et al., 2016). Nevertheless, the didactically beneficial use of VR in education still represents an important question to be answered. Nissim and Weissblueth (2017) underline that "VR in education requires a detailed pedagogical examination of situations where students can be involved with educational creations". This paper focuses on the development of a theoretical framework to foster the pedagogically beneficial use of VR in education at high school and upper secondary level. In addition, the findings will be transferred to teacher education. However, a detailed statistical analysis is not subject of this paper and will be carried out will be carried out in future research projects on the topic. In light of this, the research question being discussed in this paper is the following one: How can a theoretical framework for immersive learning be successfully integrated into teacher education?. The paper is structured as follows: the first section focuses on the modelling process: 1) What concepts can be taken into account to create a solid base for VR use in education? 2) How can a framework be developed from those concepts for the beneficial use of VR in education as a core result and contribution of this research?; the second section transfers the result to the field of teacher education and shows perspectives for future research efforts.

\section{CURRENT STATE OF RESEARCH}

Raising the status of the current state of research sets the base for the modelling of a theoretical framework supporting the didactically meaningful use of VR in education.

Virtual Reality in Education. Virtual Reality can be defined as "experience in which agents interact within a three-dimensional (3D) world with movement of their body, experiencing images and sounds" (Sherman \& Craig, 2002). Billingsley et al. (2019) defined "immersive VR" as "an advanced form of human-computer interface that allows the user to interact with and become immersed in a computer-generated environment in a naturalistic fashion". Summing up, Beck (2019) from the ILMxLAB (Lucasfilm's immersive entertainment 
studio) explained that "AR (Augmented Reality) lets you see the world differently, VR lets you see a different world". Consequently, it is important to underline, that the level of immersion and the resulting experience differs depending on the used technology. Concerning education, VR inherits the potential to "teach experientially about the real world whether in the past, present or future" (Nissim \& Weissblueth, 2017). An interesting finding is that VR environments have a notable impact on feelings and emotions due to the immersive character of the technology (Beck, 2019; Nissim \& Weissblueth, 2017). Especially when students face a complex challenge and manage to deal with it, positive emotions are unleashed. The fact that VR creates strong emotions is an important finding, which makes it very interesting for education and learning (Nissim \& Weissblueth, 2017).

Digital storytelling. Classical sotrytelling can be enriched by modern, digital media (Donert, 2017). Consequently, digital storytelling represents a combination of multimediatic elements (such as video, text, music, etc.) used to energize a clear message and classical storytelling (Robin \& McNeil, 2012). Stories naturally involve and emotionalize the participant, as they are usually written in the first person in order to hold his or her interest (Donert, 2017). A major benefit for educational purposes is the characteristic of digital stories to increase visual memory capacity (Robin \& McNeil, 2012; Wu \& Chen, 2020). Parker et al. (2016) found that VR acts very well as an enabler of digital storytelling as the participant can take action.

Immersive Learning Environments. Immersive learning represents a media-rich experience, which supports the creation of realistic real-life context simulations. It is important to mention that the level of immersion can vary from low to high density (Schmoelz, 2018). A highly immersive experience implies that the user is intensively involved with all his or her senses: Bodily, orally and visually (Schmoelz, 2018; Cooper et al., 2019). Studies revealed that first the level of immersion determinates resulting learning outcomes (Schmoelz, 2018). Secondly, also conceptual learning gains positively correlate with the level of immersion of a learning experience (Georgiou \& Kyza, 2018; Hwang et al., 2016). Thirdly, with VR and IVR (Immersive VR) embedded in the classroom, the learning satisfaction and interest in the topic was remarkably higher (Hodgson et al., 2019; Parker et al., 2016). VR platforms can have a transformative effect on education (Cooper et al., 2019). This effect has been demonstrated in a fully immersive setting but also by using 360-degree video technology displayed with VR technology support (Rupp et al., 2019).

\section{RESULTS}

\subsection{Educational Storyliving Framework}

Arising from the world of gaming, the term "Storyliving" describes an immersive experience, where there is no "one-way communication" like in classical storytelling but a real interaction instead. The user can act in and influence a virtual environment (Beck, 2019). Consequently, Storyliving can result as a suitable concept to implement immersive VR meaningfully in education. In particular because it inherits the ability to shape and create emotions (Beck, 2019). To sum up, a theoretical framework for Storyliving can be established from the findings in chapter 2 of this paper. Accordingly, "Educational Storyliving" can be defined as a combination of two concepts: (Educational) Digital Storytelling (1), describing a facilitated production of a short digital story in an educational community setting (Wu \& Chen, 2020) and highly immersive learning through high immersive density (2) (Schmoelz, 2018). This combination creates a pedagogically meaning- and useful base for the use of VR technology in education (Andone \& Frydenberg, 2019). The following illustration shows the theoretical framework:

Educational Storyliving

\begin{tabular}{|c|c|c|c|}
\hline \multicolumn{3}{|c|}{ High Immersive Density } & \multirow{3}{*}{$\begin{array}{c}\text { Digital } \\
\text { Storytelling }\end{array}$} \\
\hline \multicolumn{3}{|c|}{ High Engagement } & \\
\hline Bodily & Orally & Visually & \\
\hline 急 & Ial Real & $y-E n a b$ & g technology \\
\hline
\end{tabular}

Figure 1. Framework for Educational Storyliving. Own illustration 
"Educational Storyliving" can be implemented through the design of digital stories with an immersive character. The technical realization will be discussed in the following chapter. In consequence, this leads and enables a learning process driven by experience-making (experiential learning). To sum up, this framework can be used for upper-secondary but also for high school education.

\subsection{Storyliving in Teacher Education}

According to research from Nissim and Weissblueth (2017) and Theelen et al. (2019), VR offers potential for two specific areas in teacher education: 1) Classroom management represents an important skill to learn for every single novice teacher. In contrast to novice teachers, experienced teachers are constantly scanning the classroom. This allows them to notice events within the classroom at an early stage. 2) The further development of emotional intelligence and teaching empathy allows novice teachers to be more sensible regarding what is happening to themselves and their students in different situations (Snelson \& Hsu, 2020). VR allows the display of real-life classroom events. The feeling of presence and emotional involvement it produces could result as highly beneficial for the development of these competencies (Billingsley et al., 2019; Cooper et al., 2019). Especially when the teaching sequences are realized by using Educational Storyliving to create an active experience, learning outcomes for the students could be enhanced (Nissim \& Weissblueth, 2017). The arising question is, how to develop and technically enable digital stories in order to create Educational Storyliving. From personal experiences, a practical and cost-saving approach is to use 360-degree video technology (Theelen et al., 2019). A first example is described below:

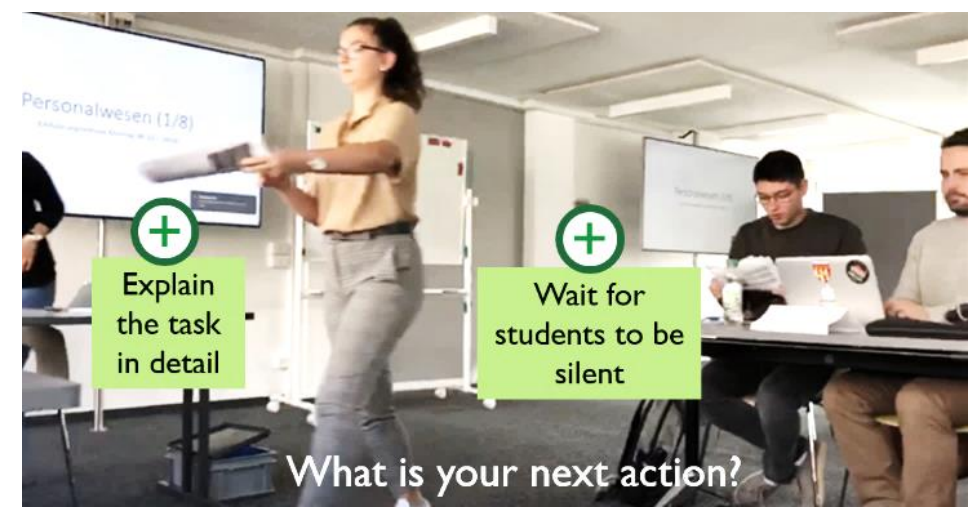

Figure 2. Example for Educational Storyliving in Teacher Education with hotspots. Own illustration

As shown in figure 2, Educational Storyliving can be used to visualize decision situations. Being bodily, orally and visually immersed in a classroom with VR, the student can actively influence the teaching scenario with his or her decisions. The scenario of the teaching sequence can thereby be supported by telling the story of a teaching unit, where you as the responsible teacher have to prepare a group task. As illustrated in the picture, your next move could be to decide whether to "explain the taks in detail" or to "wait for the students to be silent". Technically, this can be realized by using 360-degree video technology and the implementation of "hotspots" (Fig. 2) via a software solution like Omnivirt (www.omnivirt.com). Creating and programming virtual environments is much more cost intensive and would require a partnership with a specialized firm. Theelen et al. (2019) argue, that 360-degree videos are highly useful in teacher education because they allow to individually choose a specific perspective when observing classroom interactions dynamically. Furthermore, online platforms like YouTube allow to easily share 360-degree videos (Aguayo et al., 2017). Generally spoken, it is important to consider, that "well working VR environments are required for an immersive learner experience" (Theelen et al., 2019). Therefore, it is indispensable to deliberately implement the technology.

\section{CONCLUSION}

To conclude, VR may be a promising digital tool for teacher education and education in general. Based on experiences from the gaming industry and educational experts, Educational Storyliving could result as a 
suitable approach to involve students in immersive teaching experiences. This method can transform VR in a didactically powerful medium. However, there are some limitations to this research. First of all, it would be interesting and insightful if this research would be challenged from experts in other fields. My perspective on VR mainly arises from the educational sector. Secondly, the pure conceptualization and modelling of framework is only the first step. A thourough investigation of the learning outcomes represents the next, crucial footmark. Future research should consequently explore how to realise effective Educational Storyliving by creating use cases (Snelson \& Hsu, 2020). For example, STEM education may benefit from experiential learning processes supported by VR technology (Wang \& Degol, 2017). To sum up, VR differentiates itself from other teaching mediums because of its characteristic to create emotionally involving immersive experiences. Through its proper implementation into education by using a concept like Storyliving, VR unfolds its potential and allows to experientially learn in another world.

\section{REFERENCES}

Aguayo, C. et al. (2017). Key themes in mobile learning: Prospects for learner-generated learning through AR and VR. Australasian Journal of Educational Technology, Vol. 33, No. 6, pp. 27-40. DOI: https://doi.org/10.14742/ajet.3671

Andone, D. \& Frydenberg, M. (2019). Creating Virtual Reality in a Business and Technology Education Context. In Tom Dieck, C. \& Jung, T. (Eds.). Augmented Reality and Virtual Reality. The Power of AR and VR for Business, pp. 147-160. Cham: Springer Verlag.

Beck, V. D. (2019). ILMxLAB: From Storytelling to Storyliving. Retrieved from https://www.youtube.com/watch?v=Or_U3K7TmtY

Billingsley, G. et al. (2019). A Systematic Literature Review of Using Immersive Virtual Reality Technology in Teacher Education. Journal of Interactive Learning Research (JILR), Vol. 30, No. 1, pp. 65-90.

Cooper, G. et al. (2019). Using virtual reality in the classroom: preservice teachers' perceptions of its use as a teaching and learning tool. Educational Media International, Vol. 56, No. 1, pp. 1-13.

Donert, K. (2017). Literature Review on Telling Digital Stories. Salzburg: University of Salzburg.

Google News Lab. (2017). Storyliving. An ethnographical study of how audiences experience VR and what that means for journalists. Retrieved from newslab.withgoogle.com

Hodgson, P., Lee, V. Chan, J., Fong, A., Tang, C. \& Wong, C. (2019). Immersive Virtual Reality (IVR)in Higher Education. Development and Implementation. In Tom Dieck, C. \& Jung, T. (Eds.). Augmented Reality and Virtual Reality. The Power of AR and VR for Business, pp. 161-174.

Parker, M., Patton, K. \& O'Sullivan, M. (2016). Signature pedagogies in support of teachers' professional learning. Irish Educational Studies, Vol. 35, No. 2, pp. 137-153.

Nissim, Y. \& Weissblueth, E. (2017). Virtual Reality (VR) as a Source for Self-Efficacy in Teacher Training. International Education Studies, Vol. 10, No. 8, pp. 52-59.

Robin, B. \& McNeil, S. (2012). What educators should know about digital storytelling. Texas: University of Houston.

Schmoelz, A. (2018). Enabling co-creativity through digital storytelling in education. Thinking skills and creativity, Vol. 28, pp. 1-13.

Sherman, W. R., \& Craig, A. B. (2002). Understanding virtual reality: Interface, application, and design. Burlington, MA: Morgan Kaufmann.

Snelson, C. \& Hsu, Y. (2020). Educational 360-Degree Videos in Virtual Reality: A Scoping Review of the Emerging Research. TechTrends, Vol. 64, pp. 404-412.

Theelen, H. et al. (2019). Using 360-degree videos in teacher education to improve preservice teachers' professional interpersonal vision. Journal of Compuer Assisted Learning, Vol. 35, pp. 582-594.

Wang, M.-T. \& Degol, J. L. (2017). Gender Gap in Science, Technology, Engineering, and Mathematics (STEM): Current Knowledge, Implications for Practice, Policy, and Future Directions. Educational Psychological Review, Vol. 29, pp. 119-140.

Wu, J. \& Chen, D. (2020). A systematic review of educational digital storytelling. Computers \& Education, Vol. 147. 